\title{
15 Fluorescence Excitation Spectroscopy (FES) to Evaluate the Farming System's Impact on Food Quality
}

\author{
Jenifer Wohlers, Peter Stolz and Gudrun Mende \\ Forschungsinstitut KWALIS gGmbH
}

Jürgen Strube (in Memoriam)

\section{CONTENTS}

Introduction 167

The Method of FES Measurements 168

Effects of Farming Systems on Food Quality, Measured by FES................................................ 168

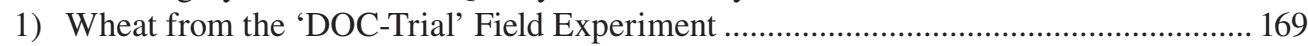

2) Apple Quality: Maturation and Growing Conditions .................................................. 170

3) Emission Spectrums as Dependent on the Type of Sample and the Sample State......... 172

4) Cocoa Beans Grown in Monocultures or in Agroforestry Systems .............................. 173

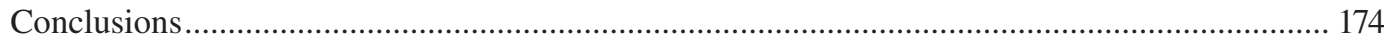

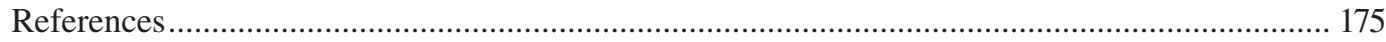

\section{INTRODUCTION}

Fluorescence Excitation Spectroscopy (FES) was developed by J. Strube in the 1980s and 1990s based on the investigations of F.A. Popp $(1984,2013)$. Popp used the term 'biophotons' for photons which were emitted by organisms at a very low intensity (ultra-low) and invisible to the human eye. Photons themselves are countable units of light, physically detectable as particles. Popp evaluated the relation between these ultra-low photon emissions - or biophotons - and human health, especially in relation to carcinogenic diseases and the quality of foodstuffs from organic farming. The inspiration for his research was provided by Gurwitsch (e.g. Gurwitsch and Gurwitsch, 1932) who, as a biologist and medical scientist, was interested in growth-stimulating effects. In his experiments on onion roots and yeast cultures, Gurwitsch found that mitosis (cell division giving rise to genetically identical cells) was encouraged by neighbouring root tips. He concluded that growing or living organisms emit light - which he named 'mitogenetic radiation' - which influences other organisms. Nowadays this is named 'ultra-weak photon emission' (UWPE) or 'ultra-low photon emission' (ULPE) and is used to describe a very weak emission of light, in wavelengths of the visible and ultraviolet light. It is now known that coloured light (special wavelengths) stimulates specific metabolic pathways in plants and humans, resulting (in the case of plants) in flowering, growing or ripening (Eichhorn Bilodeau et al., 2019; Monostori et al., 2018), or (in humans) in higher levels of alertness or fatigue (Askaripoor et al., 2018; Bauer et al., 2018; Rahman et al., 2017). 
Between the 1960s and 1980s, Popp's thesis made a comeback among some scientists in Germany. Popp argued that high-quality food contains measurable amounts of biophotons and that these could have a nutritive value for humans and may help us to stay healthy. At this time, there was growing scepticism in Europe about the supposed benefits of mineral fertilisers and synthetic pesticides. This raised the question of whether organically grown food might be qualitatively different from that which was industrially grown. In this context, FES was developed, with the aim of determining food quality in a holistic way. Differences between crop samples grown under organic and conventional conditions were explored, as well as the effects of the biodynamic preparations, which at that time were known by some farmers to be potent, but whose mechanistic pathways were not yet understood scientifically.

More recently, scientific research has confirmed the real differences in soil parameters, plant health, product quality and more, between industrial and organic/biodynamic farming (e.g. Geier et al., 2016; Mäder et al., 2006; Mie et al., 2017). Research also shows that the use of biodynamic preparations may ${ }^{1}$ result in enhanced product quality, which is measurable through picture-forming methods (Doesburg et al., 2014; Fritz et al., 2017; Bloksma et al., 2001, 2007) as well as by FES (Stolz et al., 2019; Strube and Stolz, 2010). With ongoing developments in analytical capacity, these differences can also be shown by the metabolic pattern (or 'metabolomics'; Shewry et al., 2018; Zörb et al. 2009), by 1H-NMR (nuclear magnetic resonance spectroscopy) (Picone et al., 2016) or by modern gas-chromatographic and mass-spectrometric devices (Bigot et al., 2018).

This chapter describes the general methodology of the FES measurement and provides some relevant results and reflections on the epistemology of the approach. The aim is to encourage the reader not only to think in terms of the dominant mainstream worldview that focuses on material form, but also to consider life processes. Light energy mediates such life processes and is thus also of importance when studying metabolites, and this light- and life-process-related aspect of food quality needs to be taken into consideration when evaluating FES results.

\section{THE METHOD OF FES MEASUREMENTS}

The procedure of FES consists of an illumination (excitation) of the sample and a measurement of the subsequent emission of photons (see Figure 15.1). The measurements are conducted in a climate-controlled dark room (at $15 \pm 1^{\circ} \mathrm{C}$ with $40 \pm 5 \%$ relative humidity). The excitation is done by projecting light in seven different colours (i.e. red, yellow, blue, etc.) one after the other onto the sample, each colour representing a defined range of wavelengths of visible light. Detection after each colour excitation is realised by a photomultiplier which counts the subsequent emitted photons at intervals, and the declining curve over time is documented (Figure 15.2). The data evaluation is performed on the basis of repeated measurements of each sample, and parameters such as the short-time emission (the first data point of the declining curve, Mw1) or the long-term emission (the mean of the last 40 or 80 data points of the declining curve, R40) for each excitation colour are of interest, as well as the relationships between them.

A more detailed description of the method and the devices used is given in Stolz et al. (2019) and Wohlers and Stolz (2019).

\section{EFFECTS OF FARMING SYSTEMS ON FOOD QUALITY, MEASURED BY FES}

To date, thousands of such FES measurements have been performed at the research institute KWALIS in Germany, many of which focusing on the impact of farming systems on food quality. To explain the concept of quality evaluation via FES, four examples are provided which show the following:

\footnotetext{
${ }^{1}$ The term 'may' is used here rather than 'does' because the biodynamic preparations do not work like standard industrial inputs, such as nitrogen fertiliser, and thus should not be compared to or treated as such. The preparations enhance quality in the way that is appropriate for each given situation; they encourage growth and enable other possibilities without forcing the plant.
} 


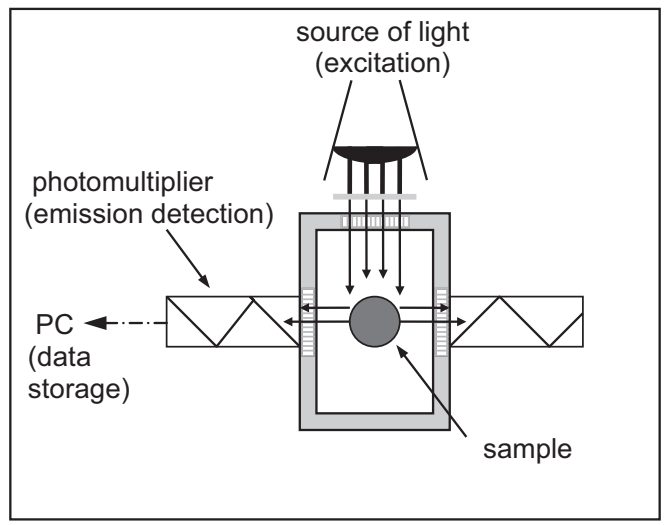

FIGURE 15.1 Schematic overview of the FES measuring apparatus with $90^{\circ}$ position between excitation illumination and emission detection by photomultipliers. The time sequence between excitation and emission is regulated by shutters.

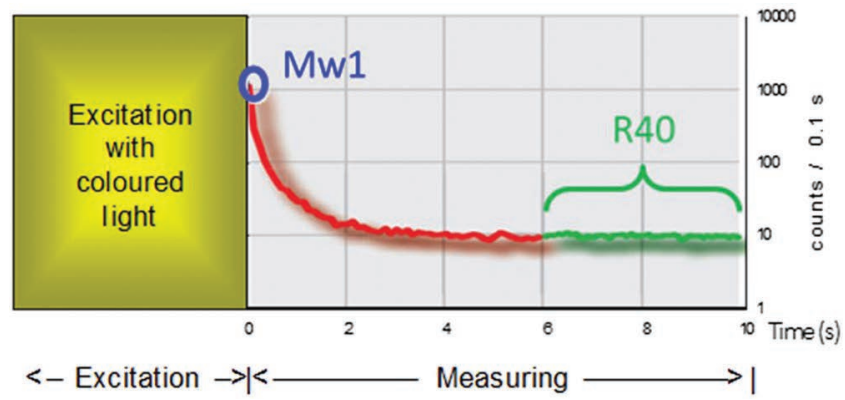

FIGURE 15.2 Schematic illustration of the excitation and measuring interval and a characteristic declining curve of the delayed emission. Mw1 indicates the short-time emission, and R40 indicates the long-term emission.

i) influences of farming systems on the induced emission of food (Nos. 1 and 4),

ii) the variation of induced emission, caused by maturation and growing conditions, and in relation to different parts of the plant (No. 2),

iii) phenomena of induced emission in relation to aspects of holistic quality (No. 3).

\section{1) Wheat from the 'DOC-Trial' Field Experiment}

The DOC-trial was established in Switzerland in 1978 to evaluate differences in yield, plant health, crop quality and soil parameters between the biodynamic farming method (represented by D2 in Figure 15.3), organic farming (without biodynamic preparations, O2) and industrial farming systems that use mineral fertilisers, either with (K2) or without (M) the additional use of manure (Mäder et al., 2002, 2006).

Wheat samples from this experiment were measured over several years by FES, and the results were published in Strube and Stolz (2010) and Hermanowski et al. (2013).

Significant $(p<0.05)$ differences between the samples were observed. The FES parameter R40yellow/blue (Figure 15.3) showed low yellow-by-blue ratios for the organic and biodynamic 


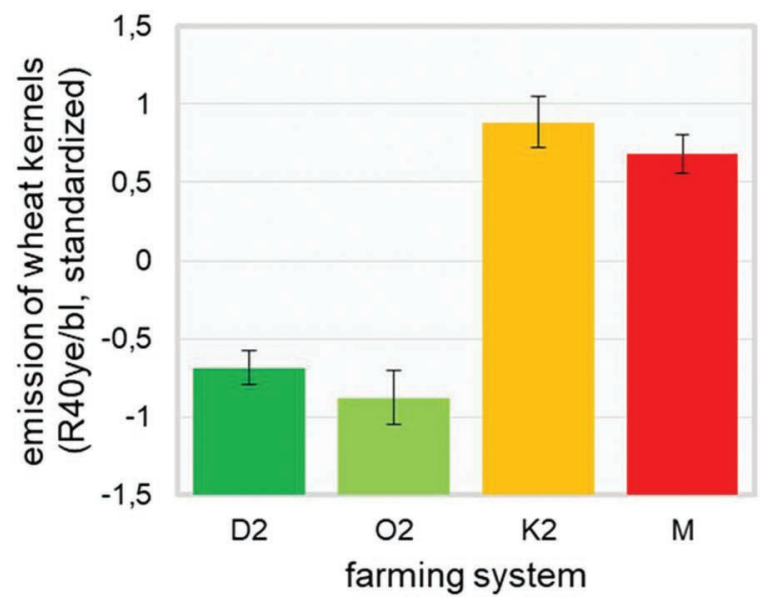

FIGURE 15.3 Differences between the wheat samples collected over 6 (O2 and K2) and 8 years (D2 and $\mathrm{M}$ ), on the basis of mean values per year and farming system (standardised by year of harvest). Whiskers indicate standard error of the mean. D2=biodynamic; O2=organic; K2=conventional (manure+mineral); $\mathrm{M}=$ mineral fertilisation only.

samples in 7 of 8 years. Other parameters, such as Mwlgreen-by-blue or R40yellow, similarly showed a difference between organic/biodynamic (D2, O2) and industrial farming systems (K2, M). Higher R40yellow/blue values (as observed in the industrial samples) can be interpreted as less maturation in seeds (Strube and Stolz, 2010) and are in accordance with other investigations on bean seeds (Strube and Stolz, 2001c) and calendula seeds (Strube and Stolz, 2001b). This yellow-by-blue parameter was determined as relevant for seeds since those in dormancy have higher biophoton emissions after blue than after yellow excitation, whereas the opposite occurs in germinating and unripe seeds (cf. also No. 2 of this chapter). Fertilisation intensity also changes this parameter to high values, which are characteristic for vegetative states where the seed has not completed the differentiating growth phase (cf. also No. 3 of this chapter).

\section{2) Apple Quality: Maturation and Growing Conditions}

An experiment with apple trees was carried out in the year 2000 in the Netherlands by the Louis Bolk Institute, to examine the effects of maturation stages, light intensities and biodynamic preparations on the quality of apples according to the 'Inner Quality Concept'2 (Bloksma et al., 2003, 2004, 2007). The whole apples as well as the kernels of the apples were measured (full results are published in Bloksma et al. (2001) and Strube and Stolz (2002)).

As the apples matured (Figure 15.4), the values in the R40yellow/blue parameter for the whole apples increased, while the seeds of these apples showed lower values. This divergence in values during seed development can be viewed in relation to the morphologically visible increasing inner differentiation of the apples from their seeds. This was also indicated by increasing amounts of secondary metabolites: the kernels became seed-typical, and the fruits became fruit-typical (cf. No. 3 of this chapter). The highest degree of quality (called 'integration' by Bloksma et al. (2003), or 'product-typical' according to our own terminology) was reached with full maturation, including a specific equilibrium between reduced growth processes (mass production, related to primary

\footnotetext{
2 The 'Inner Quality Concept' is a quality concept for food based on the life processes of growth and differentiation. It was developed to show the additional value of carefully grown organic food, to explain properties such as 'vitality' and 'coherence' and to relate to health aspects.
} 


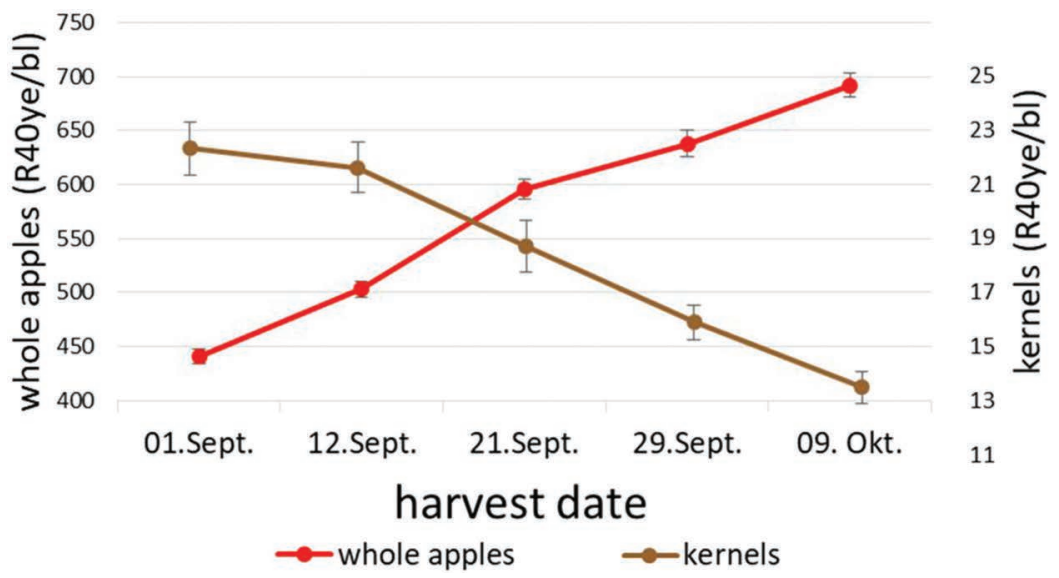

FIGURE 15.4 R40yellow/blue of whole apples and their seeds at different maturation stages. Whiskers indicate standard error of the mean. An increasing divergence of the induced emission of whole apples and their kernels during maturation was observed, these being indicated on the figure by the crossing of the lines.

metabolites) and increased differentiating processes (diversity of tissue structure and integration of small molecules into larger ones relating to secondary metabolites).

Another experiment with factors including light intensity and biodynamic preparations (Figure 15.5) showed that at full light and with biodynamic preparations, an emission with high yellow-by-blue ratios was observed, indicating that under these growing conditions, a fruit developed which was comparable to mature fruits, while shadow resulted in apples which looked as though they were not completely ripened.

Yellow/blue is the most obvious of the colour parameters in terms of excitation and can be found in several other sample sets as relevant to maturation and ripening of seeds. (Single colours are less specific to maturation, and these absolute parameters are more intensively related to, for example, the size of the sample or freshness.) The challenge of this method is that the parameter

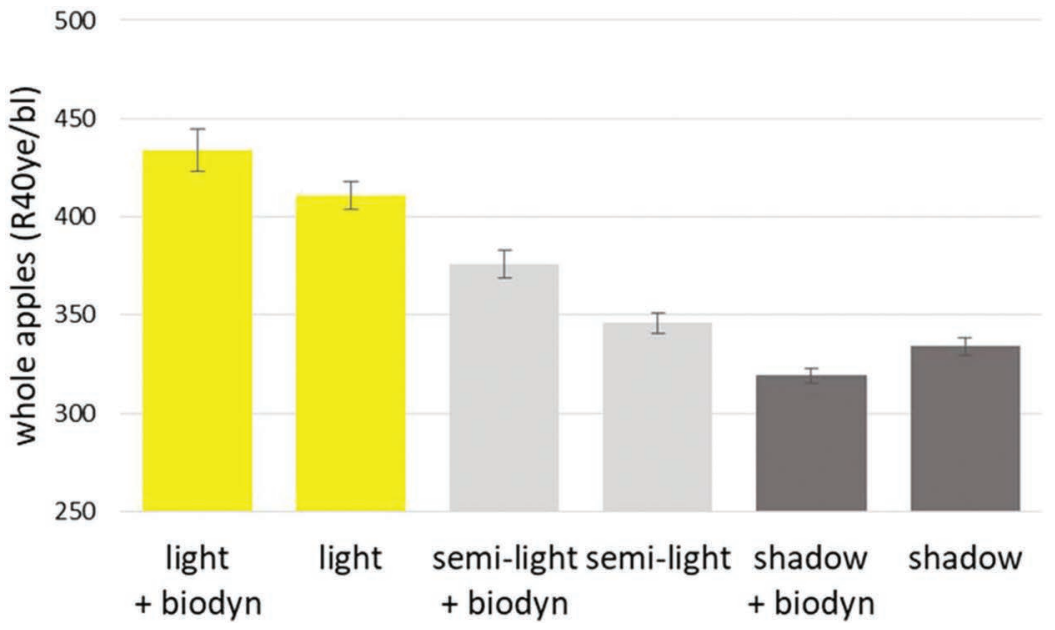

FIGURE 15.5 R40yellow/blue of whole apples from different growing conditions (light intensity and application of biodynamic preparations). 
R40yellow/blue is relative and is not a simple value for maturation, such as of the amount of secondary metabolites. It has to be interpreted depending on the sample: the sample type, the plant's organs such as e.g. seed, fruit, leaf have to be considered, and the evaluation scale has to be obtained from the object itself. As the maturation stages of fruits are the plant's steps on its way to its characteristic well-formed, well-shaped, evolved final stage of development before it decays in several stages to death, it can be seen that the different organs differ with progressing maturation, and the FES results represent this. Strube and Stolz (2002) concluded that this development can be interpreted as an increased differentiating, organisational capacity or performance (in German: Organisationsleistung, cf. also Egerer, 2009) and that it was present in the apples grown under full light or in those with biodynamic preparations (Figure 15.5; Strube and Stolz, 2002). In other situations, such as where the crop is intensively fertilised or grown in in vitro cultivation, growth showed less differentiation.

\section{3) Emission Spectrums as Dependent on the Type of Sample and the Sample State}

To compare the different characteristics of the spectrally excited emissions of different kinds of samples, measurements have to be performed at the same excitation intensity and the same measuring intervals, which normally have to be set specifically due to different emission intensities of different kinds of samples. It was observed that leaves expressed an intense emission after being subjected to all excitation colours (the most after yellow or red excitation) - and this is named a 'broadband spectra' (cf. Figure 15.6) - whereas a pure chemical substance like citric acid only showed considerable emission after blue excitation - which is a narrowband spectra. Seeds (wheat grains) fell in between these characteristics - they had a low emission when excited with yellow or red light and an intermediate emission after excitation with blue light. These spectra are of importance when evaluating quality in the context of the sample's natural state, that is the whole mass of substances of the sample that are present at the moment of detection (including its life processes and specific composition of substances and physiological processes).

Strube and Stolz (2004) have also observed that when seeds are not totally dried, they may emit more like a leaf, with higher emission intensity after yellow or red excitation - as they are not yet in total dormancy and thus their physiology is more active. Further, when wheat was grown with higher amounts of nitrogen fertiliser, resulting in higher amounts of crude protein in the wheat

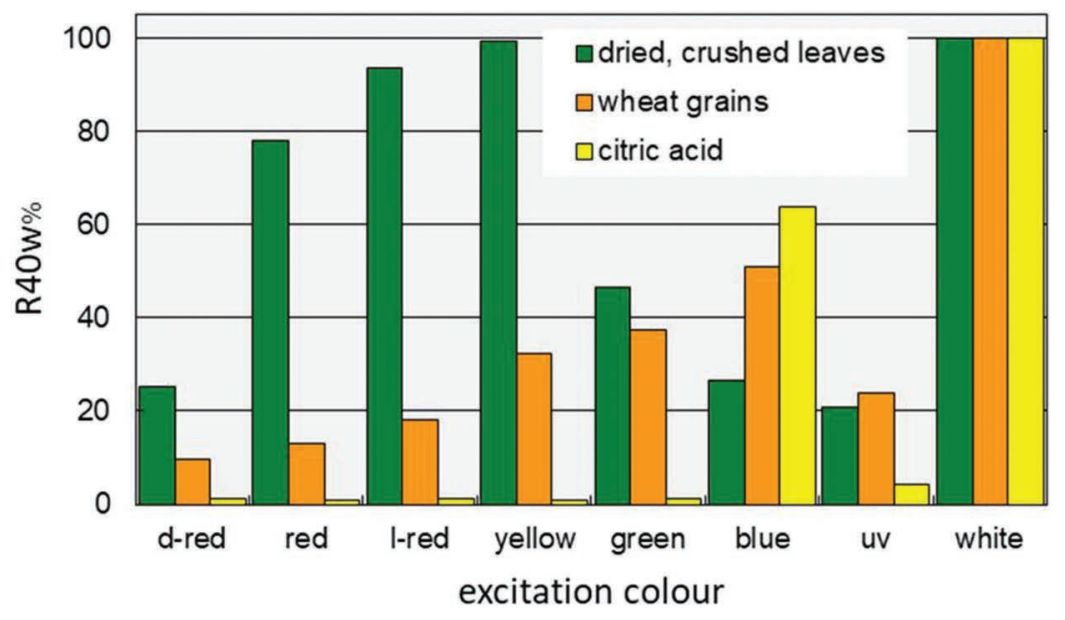

FIGURE 15.6 Fluorescence excitation spectrum of different kinds of samples: emission of leaves (dried crushed nettle leaves), of seeds (whole wheat kernels) and of citric acid. (Derived from Strube and Stolz, 2001a.) 
kernels, its emissions were similar to those of a vegetative in-growth state, while the emissions of other samples were more dormant and seed-like. This indicates that the excitation spectroscopy can detect whether growing and ripening were performed and finished by the plant's own characteristic physiology under natural conditions, or whether it was influenced by fertilisers or other physiology-influencing factors.

On the basis of these results, it can be concluded that the biophoton emission after colour excitation can indicate whether the sample is in a more or less characteristic state,

- being more leaf-like, representing vegetative growth-processes,

- being more seed-like, representing generative, mature, dormant situations, where physiological processes are reduced, resulting in conservation and storage of growth-relevant substances,

- or being more like a pure chemical substance, representing minerals which are not actually integrated in life processes.

\section{4) Cocoa Beans Grown in Monocultures or in Agroforestry Systems}

A scientifically controlled field trial with cocoa plants was installed in 2009 in Bolivia (Sara Ana, near La Paz), to compare the effects of the farming system on ecological aspects (biodiversity), soil parameters, plant health and product quality. The experimental factors were as follows: (1) monoculture (Mono) vs. agroforestry (AF) farming and (2) conventional (Conv) vs. organic (Org) farming; additionally, a successional agroforestry system (SAFS) was investigated. FES measurements were performed on fermented cocoa beans which were harvested in 2012.

The results are provided in Figure 15.7 for the five farming systems in comparison, and in Figure 15.8, the differences between organic and conventional systems are presented.

The emission of the cocoa beans - although fermented - showed a comparable spectral excitation ability to wheat kernels. Organic and agroforestry (AF) farming systems resulted in lower long-term emission intensities after yellow excitation (Figure 15.7), indicating a more seed-typical quality. The ratio between yellow and blue (R40yellow/blue; Figure 15.8) was higher among the conventional samples than among the organic samples and may indicate a seed with a low degree of specific maturity, again comparable to the conventional wheat samples (K2 and M) from the DOC-trial. The low values of the organic samples may indicate that the seeds reached seed-typical qualities.

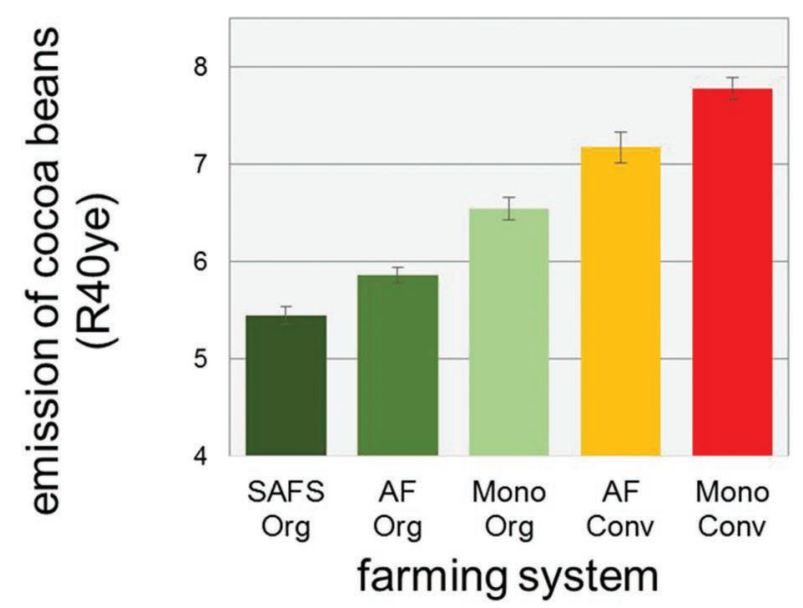

FIGURE 15.7 Emission intensity (R40yellow) of fermented whole cocoa beans from a cultivation trial. Whiskers indicate standard error of the mean. 


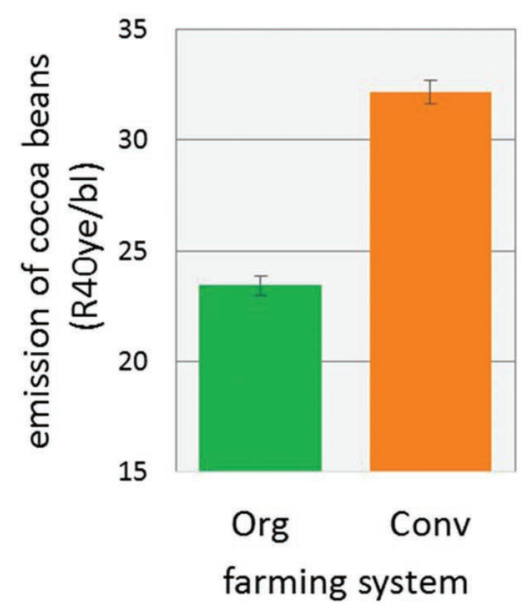

FIGURE 15.8 Differences between conventional and organic farming in cocoa beans in the relative emission intensity of R40yellow/blue.

The SAFS sample had an overall very low emission intensity, characteristic for seeds in dormancy or grown under extensive conditions. Overall, the implications are that more sustainable farming systems are better able to produce or achieve products that are closer to their optimum, naturally predisposed potential.

\section{CONCLUSIONS}

The FES has repeatedly been able to show differences between samples originating from different farming systems, and a classification of samples according to their origin has been possible, which was comparable to the classification on the basis of their analytical parameters (Hermanowski et al., 2013). It will be just a question of time before the underlying principles of the induced emission characteristic are better understood. Still, the existing results of the FES measurements are sufficient to support the rationale that the scientific view should be broadened to look not only at the microscopic and analytical world, but also at the phenomena of life and, holistically, at the farming system as a whole that influences the organisms within it and their development, their metabolism and interactions.

A theory common among biologists is that plants seek a balance between growth and differentiation (Bloksma et al., 2003, 2007; Herms and Mattson, 1992; Stamp, 2003). This is based on the evidence that plants may - dependent on the growing conditions - express a more growth-related metabolism with enhanced nitrogen-related primary metabolism, resulting in enhanced yields, or a metabolism which aims at the differentiation of matter by enhancing carbon-related secondary metabolites. The latter is often observed in plants of organic origin, and such plants are observed to suffer less damage from predators or diseases (de Lange et al., 2019). This balance or equilibrium changes with the ongoing development of the plant, from more growth-related to more differentiation-related processes, and each part of the plant and each species has its own characteristic balance.

So when FES results indicate that crop samples of organic, biodynamic or agroforestry origin are 'more typical' than conventional/industrial samples, including those from monocultures, the measured emission can be seen as an indication of the growing conditions which were more or less in congruence with the species-specific demands. Under such optimum conditions, plants may express their own individual quality and shape more explicitly than in less optimal conditions. For example, in highly fertilised, conventional or monoculture conditions, where the plants are restricted in their resilience to stay healthy (Döring et al., 2012, 2015), or to exhibit all stages of 
development (Bloksma et al., 2007; Lammerts van Bueren and Hospers, 1991), they are forced into a specific growth-related development.

In all investigations with FES, the relative emission after blue excitation and yellow excitation seems to be important in evaluating the sample's quality and metabolic state. Yet it is not just expressing a metabolism which is related either to more differentiation (indicated by secondary metabolites) or to more growth (indicated by primary metabolites). It also has to be interpreted in relation to the type of sample and its biologically predefined physiology. A leaf is most leaf-like when it enhances the carbon metabolism of the plant by photosynthesis, when it expresses life processes. Fruits are most fruit-like when they are ripening and store sugar and polyphenols - also products of life processes. In these cases, high emissions after excitation with red or yellow can be observed, and high ratios of yellow-by-blue are characteristic. The opposite is found for seeds: their emission after red or yellow excitation declines with ripening - so for seeds, a high emission indicates a metabolism which is not seed-like - it is growth-like or life-like, but not dormant, as a seed should be when it is in its typical state. So with FES, the typical expression of a plant's organ may be evaluated in terms of its state of expressing its own, naturally desired condition, its metabolic state, seen as the operating processes of life.

On the basis of this ability of the FES to tell us something about the plant's life processes, it may in the future be used not only to differentiate between farming systems, but also to help farmers or scientists to decide which farming practice is helpful in obtaining the best quality product, or which breeding line offers the most product-typical opportunities.

\section{REFERENCES}

Askaripoor, T., Motamedzadeh, M., Golmohammadi, R., Farhadian, M., Babamiri, M. and Samavati, M. (2018) Non-image forming effects of light on brainwaves, autonomic nervous activity, fatigue, and performance. J Circadian Rhythms 16:1-13.

Bauer, M., Glenn, T., Monteith, S., Gottlieb, J.F., Ritter, P.S., Geddes, J. and Whybrow, P.C. (2018) The potential influence of LED lighting on mental illness. World J Biol Psychiatry 19:59-73.

Bigot, C., Métivier, R., Montet, D. and Meile, J.-Chr. (2018) Traceability and authentication of organic foodstuffs, Chapter 6. In: Montet, D. and Ray, R.C. (eds), Food Traceability and Authenticity: Analytical Techniques, pp. 116-136. Boca Raton, FL: CRC Press/Taylor \& Francis.

Bloksma, J., Northolt, M. and Huber, M. (2001) Parameters for Apple Quality: Part 2-Annexes. Driebergen: Louis Bolk Instituut.

Bloksma, J., Huber, M., Northolt, M., van der Burgt, G.J. and Adriaansen-Tennekens, R. (2003). The Inner Quality Concept for food, Based on Life Processes. Driebergen: Louis Bolk Instituut. http://orgprints. org/4894\%.

Bloksma, J., Northolt, M., Huber, M., Jansonius, P. and Zanen, M. (2004). Parameters for Apple Quality - 2, and the Development of the 'Inner Quality Concept' 2001-2003. Driebergen: Louis Bolk Instituut. http://orgprints.org/4266/.

Bloksma, J., Notholt, M., Huber, M., van der Burgt, G.-J. and van de Vijver, L. (2007) A new food quality concept based on life processes. In Cooper, J., Leifert, C. and Niggli, U. (eds), Handbook of Organic Food Safety and Quality. Cambridge: Woodhead Publishing. http://www.louisbolk.org/downloads/1910.pdf.

De Lange, E.S., Kyryczenko-Roth, V., Johnson-Cicalese, J., Davenport, J., Vorsa, N. and Rodriguez-Saona, C. (2019) Increased nutrient availability decreases insect resistance in cranberry. Agric Forest Entomol 21: $326-335$.

Doesburg, P., Huber, M., Andersen, J.O., et al. (2014) Standardization and performance of a visual Gestalt evaluation of biocrystallization patterns reflecting ripening and decomposition processes in food samples. Biol Agric Hort 31:128-145.

Döring, T.F., Pautasso, M., Finckh, M.R. and Wolfe, M.S. (2012) Concepts of plant health: Reviewing and challenging the foundations of plant protection. Plant Pathol 61:1-15.

Döring, T.F., Vieweger, A., Pautasso, M., Vaarst, M., Finckh, M.R. and Wolfe, M.S. (2015) Resilience as a universal criterion of health. Sci Food Agric 95:455-65.

Egerer, U. (2009) Feldstudie zur Eignung der Biophotonenmessung für die Differenzierung von ökologisch und konventionell erzeugten Hühnereiern [Field Study on the Suitability of the Biophoton Measurement for the Differentiation of Organically and Conventionally Produced Chicken Eggs]. PhD dissertation, University of Hohenheim. http://opus.ub.uni-hohenheim.de/volltexte/2009/404/. 
Eichhorn Bilodeau, S., Wu, B.-S., Rufyikiri, A.-S., MacPherson, S. and Lefsrud, M. (2019) An update on plant photobiology and implications for cannabis production. Front Plant Sci 10:296.

Fritz, J., Athmann, M., Meissner, G., Kauer, R. and Köpke, U. (2017) Quality characterisation via image forming methods differentiates grape juice produced from integrated, organic or biodynamic vineyards in the first year after conversion. Biol Agric Hort 33:195-213.

Geier, U., Fritz, J., Greiner, R. and Olbrich-Majer, M. (2016) Biologisch-dynamische Landwirtschaft [Bio-Dynamic Agriculture] (Chapter 4). In Freyer, B. (ed.), Ökologischer Landbau - Grundlagen, Wissensstand und Herausforderungen, pp. 101-23. Stuttgart: UTB Taschenbuch.

Gurwitsch, A. and Gurwitsch, L. (1932) Die mitogenetische Strahlung. Zugleich zweiter Band der "Probleme der Zellteilung" [The Mitogenetic Radiation. And 2nd Part of the "Problems of Cell Division"]. (Monographien aus dem Gesamtgebiet der Physiologie der Pflanzen und der Tiere. Band 25). Berlin: Justus Springer.

Hermanowski, R., Boner, M., Bonte, A., Bonte, A., Henryson, A.S., Hofem, S., Langkämper, G., Mäder, R., Mende, G., Neuendorff, J., Niehaus, K., Stolz, P. and Strube, J. (2013) Weiterentwicklung und Nutzungsempfehlung ausgewählter Methoden zur Unterscheidung von ökologischen und konventionellen Produkten [Evaluation and recommendation of further use of selected methods for determining organic and conventional products]. Frankfurt: Forschungsinstitut für biologischen Landbau (FiBL). http://orgprints.org/22444/.

Herms, D.A. and Mattson, W.J. (1992) The dilemma of plants: To grow or defend. Q Rev Biol 67:283-335.

Lammerts van Bueren, E. M. and Hospers, M. (1991) Technologisch groen versus biologisch groen -een onderzoek naar de kwaliteit van industrieel en biologisch-dynamisch geteelde pluksla [Technologically Green Versus Organically Green: An Investigation into the Quality of Industrially and Biodynamically Grown Pickled Lettuce]. Driebergen: Louis Bolk Instituut.

Mäder, P., Fliessbach, A., Dubois, D., Gunst, L., Fried, P. and Niggli, U. (2002) Soil fertility and biodiversity in organic farming. Science 296:1694-1697.

Mäder, P., Fliessbach, A., Dubois, D. et al. (2006) The DOK experiment (Switzerland). In Raupp, J., Pekrun, C., Oltmanns, M. and Köpke, U. (eds), Long-term Field Experiments in Organic Farming, pp. 41-58. Berlin: Dr. Köster, Scientific Series; Int. Society of Organic Agriculture Research (ISOFAR).

Mie, A., Andersen H.R., Gunnarsson S., Kahl, J., Kesse-Guyot, E., Rembialkowska, E., Quaglio G. and Grandjean, P. (2017) Human health implications of organic food and organic agriculture: a comprehensive review. Environ Health 16:111.

Monostori, I., Heilmann, M., Kocsy, G., Rakszegil, M., Ahres, M., Altenbach, S.B., Szalai, G., Pál, M., Toldi, D., Simon-Sarkadi, L., Harnos, N., Galiba, G. and Darko, E. (2018) LED lighting: Modification of growth, metabolism, yield and flour composition in wheat by spectral quality and intensity. Front Plant Sci 9:605.

Picone, G., Trimigno, A., Tessarin, P., Donnini, S., Rombola, A.D. and Capozzi, F. (2016). 1H NMR foodomics reveals that the biodynamic and the organic cultivation managements produce different grape berries (Vitis vinifera L. cv. Sangiovese). Food Chem 213:187-195.

Popp, F.-A. (1984) Biologie des Lichts - Grundlagen der ultraschwachen Zellstrahlung [Biology of Light Basics of ultra-weak Cell Radiation]. Berlin: Paul Parey.

Popp, F.-A. 2013. Biophotons: Background, experimental results, theoretical approach and applications. In: Popp, F.-A. and Beloussov, L.V. (eds) Integrative Biophysics: Biophotonics, pp. 386-438. Berlin: Springer Science and Business Media.

Rahman, S.A., Hilaire, M.A. St. and Lockley, S.W. (2017) The effects of spectral tuning of evening ambient light on melatonin suppression, alertness and sleep. Physiol Behav 177:221-229.

Shewry, P., Rakszegi, M., Lovegrove, A., Amos, D., Corol, D. I., Tawfike, A., Miko, P. and Ward, J. L. (2018) Effects of organic and conventional crop nutrition on profiles of polar metabolites in grain of wheat. $J$ Agric Food Chem 66:5346-5351.

Stamp, N. (2003) Out of the quagmire of plant defense hypotheses. Q Rev Biol 78:23-55.

Stolz, P., Wohlers, J. and Mende, G. (2019) Measuring delayed luminescence by FES to evaluate special quality aspects of food samples: An overview. Open Agric 4:410-417.

Strube, J. and Stolz, P. (2001a) Lichtspeicherung und Lebensmittelqualität [Light storage and food quality]. Ökologie Landbau 117:15-19. http://orgprints.org/1960/.

Strube, J. and Stolz, P. (2001b) Untersuchungen zur Qualität von Calendula-Samen mittels zeitaufgelöster Fluoreszenz-Anregungs-Spektroskopie [Investigations to evaluate Quality of Calendula-Seeds by timeresolved Fluorescence-Excitation-Spectroscopy], Speech at: Jena: 36. Vortragstagung der Deutschen Gesellschaft für Qualitätsforschung e.V. http://orgprints.org/2332. 
Strube, J. and Stolz, P. (2001c) Bohne ist nicht gleich Bohne [Not all beans are created equal]. Ökologie Landbau 120:37-39.

Strube, J. and Stolz, P. (2002) Fluoreszenz-Anregungs-Spektroskopie zur Bestimmung der Qualität von Äpfeln aus ökologischem Anbau [Fluorescence-excitation-spectroscopy for determination of quality of apples from organic farming]. Speech at the 37th Conference Vortragstagung der Deutschen Gesellschaft für Qualitätsforschung e.V., Hannover, 04.03.2002-05.03.2002, pp. 209-214. http:// orgprints.org/00002335/.

Strube, J. and Stolz, P. (2004) Lebensmittel vermitteln Leben [Food Mediates Life]. Dipperz: KWALIS Qualitätsforschung Fulda.

Strube, J. and Stolz, P. (2010) The application of fluorescence excitation spectroscopy of whole samples for identification of the culture system of wheat and carrots: Method, validation, results. Biol Agric Hort 27:59-80.

Wohlers, J. and Stolz, P. (2019) Differentiation between milk from low-input biodynamic, intermediate-input organic and high-input conventional farming systems using fluorescence excitation spectroscopy (FES) and fatty acids. Biol Agric Hort 35:172-186.

Zörb, C., Niehaus, K., Barsch, A., Betsche, T. and Langenkämper, G. (2009). Level of compounds and metabolites in wheat ears and grains in organic and conventional agriculture. J Agric Food Chem 57: 9555-9562. 